\title{
MONITORIA ACADÊMICA EM ZOOLOGIA DOS INVERTEBRADOS: UM RELATO DE EXPERIÊNCIA
}

\author{
ACADEMIC MONITORING IN ZOOLOGY OF INVERTEBRATES: AN EXPERIENCE REPORT \\ SEGUIMIENTO ACADÉMICO EN ZOOLOGÍA DE INVERTEBRADOS: UN INFORME DE \\ EXPERIENCIA
}

\section{Marianne Martins dos Santos Pereira \\ iD 9}

Graduanda em Ciências Biológicas pela Universidade Estadual de Alagoas (UNEAL)

m.mariannemart@gmail.com

\section{João Pedro Silva Oliveira (iD) 9}

Graduando em Ciências Biológicas pela Universidade Estadual de Alagoas (UNEAL)

jpoliveira875@gmail.com

\section{Rodrigo Almeida Pinheiro (iD) 9}

Mestrando em Produção Vegetal (UFVJM)

Discente do programa de pósgraduação em Produção Vegetal pela Universidade Federal dos Vales do Jequitinhonha e Mucuri (UFVJM) rodrigo6450@gmail.com

\section{Claudimary Bispo dos Santos (iD) 9}

Mestrado em Ciências da Saúde (UFS)

Professora da Universidade Estadual de Alagoas (UNEAL) claudimarybs@hotmail.com

\begin{abstract}
Resumo
$\mathrm{Na}$ disciplina de zoologia dos invertebrados, compete ao monitor, na parte prática, exercer suas funções de auxiliar, mediar, socializar, lecionar e pesquisar. O artigo objetiva relatar experiências vivenciadas na monitoria acadêmica de zoologia dos invertebrados, discorrendo, principalmente, acerca das metodologias desenvolvidas. Nesse sentido, foi disponibilizada uma aula prática após o estudo teórico de cada filo do reino animal. A maioria dessas práticas foram desenvolvidas no laboratório multidisciplinar da universidade e neste artigo foram descritas cinco delas, relacionadas com os seguintes conteúdos: Protozoa, Porifera, Mollusca e Arthropoda. Participaram das aulas os alunos matriculados nas disciplinas de zoologia dos invertebrados I e II. Estes mostraram interesse, curiosidade e atenção durante os momentos de visualização no microscópio, revisão, dissecação e montagem da coleção dos artrópodes. Portanto, conclui-se que a monitoria contribui tanto para a formação acadêmica dos monitores quanto para um melhor andamento da disciplina, favorecendo o desenvolvimento das metodologias aplicadas.
\end{abstract}

Palavras-chave: Aulas práticas. Metodologias. Docência.

Recebido em: 31 de maio de 2021.

Aprovado em: 16 de novembro de 2021.

Como citar esse artigo (ABNT):

PEREIRA, Marianne Martins dos Santos et al. Monitoria acadêmica em zoologia dos invertebrados: um relato de experiência. Revista Prática Docente, v. 6, n. 3, e090, 2021. http://doi.org/10.23926/RPD.2021.v6.n3.e090.id1202 


\begin{abstract}
In the discipline of zoology of invertebrates, it is up to the monitor, in the practical part, to perform its functions of assisting, mediating, socializing, teaching and researching. The article aims to report the experiences experienced in the academic monitoring of zoology of invertebrates, reporting, mainly, on the methodologies developed. Thus, to facilitate the understanding of the contents of zoology, a practical class was made available after the theoretical study of each phylum of the animal kingdom. Most of these practices were developed in the multidisciplinary laboratory of the university and in this article, five of them were described, related to the following contents: Protozoa. Porifera, Mollusca and Arthropoda. Students enrolled in the zoology disciplines of invertebrates I and II participated in the classes, these students showed interest, curiosity and attention during the moments of visualization under the microscope, revision, dissection and mount of the arthropod collection. Therefore, it is concluded that monitoring contributes both to the academic training of monitors and to a better progress of the discipline, favoring the development of applied methodologies.
\end{abstract}

Keywords: Practical classes. Methodologies. Teaching.

\title{
Resumen
}

En la disciplina de zoología de los invertebrados, corresponde al monitor, en la parte práctica, desempeñar sus funciones de auxiliar, mediación, socialización, enseñanza e investigación. El artículo tiene como objetivo informar experiencias experimentadas en el seguimiento académico de la zoología de los invertebrados, principalmente sobre las metodologías desarrolladas. En este sentido, se puso a disposición una clase práctica después del estudio teórico de cada filo del reino animal. La mayoría de estas prácticas se desarrollaron en el laboratorio multidisciplinario de la universidad y en este artículo, cinco de ellos fueron descritos, relacionados con los siguientes contenidos: Protozoa. Porifera, Mollusca y Arthropoda. Los estudiantes matriculados en las disciplinas de zoología de los invertebrados I y II participaron en las clases, estos mostraron interés, curiosidad y atención durante los momentos de visualización bajo el microscopio, revisión, disección y montaje de la colección de artrópodos. Por lo tanto, se concluye que el monitoreo contribuye tanto a la formación académica de los monitores como a un mejor progreso de la disciplina, favoreciendo el desarrollo de las metodologías aplicadas.

Palabras clave: Clases prácticas. Metodologías. Enseñanza. 


\section{INTRODUÇÃO}

As instituições de ensino superior dispõem de procedimentos que viabilizam a aprendizagem de uma profissão e, por isso, são conhecidas por demandar um aprendizado minucioso e de longa duração. Dessa forma, os discentes podem obter sucesso quando incorporados às práticas e à cultura universitária presentes na instituição (RAMALHO, 2006).

O aperfeiçoamento do discente no curso de licenciatura pode acontecer por meio de sua participação em programas ofertados pela universidade, e um deles é a monitoria. Esta modalidade de programa institucional vem se consolidando no Brasil desde 1968, ano em que foi criada a Lei $\mathrm{n}^{\circ} 5.540$, na qual constava o art. 41 que era voltado para a prática de monitoria no ensino superior (SILVEIRA; SALES, 2016).

A participação neste programa é extremamente relevante para a construção de uma aprendizagem da docência e para o crescimento acadêmico do discente (SILVA, 2018; FERNANDES et al., 2016), visto que, ao desempenhar suas atividades o monitor consegue aprofundar o conhecimento na área em que está trabalhando, contribuindo para sua própria aprendizagem e também para a dos alunos monitorados. Além de vivenciar experiências pedagógicas e acadêmicas que propiciam aos estudantes a oportunidade de aprimorar habilidades essenciais na docência (ASSIS et al., 2006).

Conforme Silveira e Sales (2016), um dos objetivos do monitor é auxiliar nas atividades de uma disciplina com o intuito de aperfeiçoar o seu ensino e aprendizagem. Nesse sentido, é notória a relevância da monitoria no ensino superior como uma estratégia de ensino que habilita os discentes na atuação de sua futura profissão (LIRA et al., 2015).

Zoologia dos invertebrados é um componente obrigatório da grade curricular do curso de licenciatura em ciências biológicas e sua estrutura metodológica está ancorada em dois procedimentos didáticos: aulas teóricas, efetuadas dentro da sala de aula, e aulas práticas, geralmente desenvolvidas em laboratório. Compete ao monitor atuar naquilo que constitui o núcleo prático no qual desempenha suas funções, sendo elas a de auxiliar o professor orientador nas atividades docentes compostas pela tríade: socializar, lecionar e pesquisar.

Da mesma maneira que é importante a promoção de metodologias que facilitem a compreensão de zoologia, o material científico extraído dessa vivência da monitoria também é de grande valia para a comunidade acadêmica. Assim, como destacado por Araújo-de-Almeida et al. (2019), a difusão de relatos de experiências em eventos, cursos, periódicos, livros e outros meios científicos apresenta-se como objeto de interesse para a constituição de saberes e 
divulgação de ideias, diante da colaboração para aprendizagem de conteúdos e enriquecimento de currículos, esta modalidade de trabalho acadêmico consegue evidenciar a importância da vivência perante tantas realidades.

Em virtude do exposto e da significativa contribuição das experiências de monitoria para a academia, o presente artigo tem o objetivo relatar as experiências vivenciadas na monitoria acadêmica da disciplina de Zoologia dos Invertebrados, como forma de discorrer sobre as metodologias desenvolvidas e as habilidades adquiridas.

\section{REFERENCIAL TEÓRICO}

Partindo de um princípio fundamentado em políticas educacionais, em 1968, no Brasil, foi sancionada a lei n. ${ }^{\circ} 5.540$, que "Fixa normas de organização e funcionamento do ensino superior e sua articulação com a escola média, e dá outras providências". Nesse documento, consta o artigo 41 que estabelece: "As universidades deverão criar as funções de monitor para alunos do curso de graduação que se submeterem a provas específicas, nas quais demonstram capacidade de desempenho em atividades técnico-didáticas de determinada disciplina". Posteriormente a referida lei foi revogada para a $n^{\circ} 9.394$ de 20 de dezembro de 1996 determinando no artigo 84 que os discentes poderiam ser aproveitados para atividades de ensino e pesquisa da universidade, exercendo a função de monitor.

Segundo o Ministério da Educação (2001), esse programa é considerado uma atividade complementar para os cursos de graduação. Sendo assim, nos cursos de licenciatura, a monitoria acadêmica dispõe, principalmente, de duas funções: iniciação do aluno na docência e a contribuição para a melhoria do ensino da graduação. Dessa forma, as universidades que oferecem o programa de monitoria assumem o compromisso de proporcionar ao acadêmico uma formação mais abrangente e zelar pela qualidade de sua formação como futuro docente (NUNES, 2007).

Ao longo do tempo, as atividades de monitoria foram devidamente registradas através dos relatos de experiência. Conforme Suárez e Flores (2017), toda narrativa de experiência revela um conhecimento e intervenção no mundo e, desse modo, os relatos produzidos a partir da realidade da sala de aula podem ser úteis para que o professor continue aperfeiçoando seu desempenho docente. Araújo-de-Almeida et al. (2019) destaca a importância do processo pedagógico reflexivo associado à exploração e divulgação de ideias no contexto científico e expõe em seu trabalho um levantamento de relatos de experiências que foram divulgados e estavam focados em explorar didaticamente os assuntos de zoologia dos invertebrados. 
Araújo-de-Almeida (2012) também apresenta um trabalho que envolve as experiências desenvolvidas por estudantes universitários que cooperaram com professores de cursos de zoologia. Nesse cenário, a autora considera os relatos de experiências envolvendo os discentes do ensino superior como autores na constituição e divulgação de suas ideias (ARAÚJO-DEALMEIDA et al., 2011; DIAS-DA-SILVA, 2018). Essa produção de narrativa científica configura, segundo Passeggi (2016), um elemento investigativo essencial e devidamente reconhecido pela pesquisa autobiográfica.

Além dessas importantes funções na vida acadêmica, também é salientado por Zen e Linzmeier (2018) que as atividades de monitoria em zoologia dos invertebrados foram fundamentais para o desenvolvimento de projetos de extensão, e, dessa forma, foi possível ampliar o público que tem acesso a esses assuntos, disseminando o que é estudado e pesquisado dentro da universidade.

\section{Metodologia}

O trabalho ora exposto trata-se de um artigo de cunho descritivo, do tipo relato de experiência, e tem como finalidade a descrição das atividades de monitoria realizadas na Universidade Estadual de Alagoas (UNEAL), durante o ano de 2019, com participação de três alunos monitores e dos discentes matriculados nas disciplinas de Zoologia dos Invertebrados I (2019.1) e Zoologia dos Invertebrados II (2019.2).

As disciplinas Zoologia dos Invertebrados I e Zoologia dos Invertebrados II são ofertadas, respectivamente, no terceiro e quarto períodos do curso de Ciências Biológicas da UNEAL. Cada uma dispõe de uma carga horária de 80h, a qual é dedicada em sua maior parte às aulas teóricas, contendo também, por se tratar de licenciatura, uma parcela significativa de tempo para a realização de aulas práticas.

Conforme Brusca et al. (2018), há uma estimativa de que vivem atualmente em nosso planeta cerca de 2.007.702 de espécies, e para que haja um conhecimento taxonômico sobre estes seres vivos, cada um deles, descritos e nomeados, pertencem a uma classificação, ordenada em um padrão de subordinação. Em um dos níveis mais elevados dessas espécies existem os reinos, sendo um deles reconhecido como Animalia/Metazoa, que constitui o foco de estudo da zoologia, e, contido neste reino, existem outros graus classificatórios.

As aulas dessa disciplina tiveram como base essa classificação das espécies, com o ensinamento dos filos incluídos no reino Animalia. Eram eles, respectivamente: Porifera, Cnidaria, Ctenophora, Nematoda, Mollusca, Annelida, Arthropoda e Echinodermata. Além do 
estudo de alguns grupos mais comuns do reino protista, posto que, segundo Brusca et al. (2018), é uma tradição incluir os protistas nos cursos de zoologia dos invertebrados.

Com o intuito de dinamizar a compreensão desses conteúdos, a docente responsável pela disciplina, com a ajuda dos três monitores, realizava uma aula prática após o estudo teórico de cada filo, buscando aproveitar ambas as modalidades de aulas. Essas práticas, em sua maioria, ocorreram no laboratório multidisciplinar da universidade e na sala de aula por meio de atividades diversificadas para problematização dos conteúdos dados.

No tempo previsto no cronograma de atividades planejado com a orientadora, foi possível realizar sete aulas práticas e quatro aulas de revisão de conteúdo, totalizando 11 atividades de monitoria, ao longo dos dois períodos de 2019, correspondendo a uma turma por período. Dentre essas aplicações, o presente artigo relatou cinco atividades práticas, duas executadas durante a disciplina de Zoologia dos Invertebrados I e três durante a disciplina de Zoologia dos Invertebrados II.

As disciplinas contavam com a presença de 35 alunos em cada turma, os quais foram avaliados em todas as atividades práticas, utilizando-se os seguintes critérios: participação, dedicação, compromisso, relações de convivência e desempenho no laboratório. Além disso, também era realizada uma avaliação descritiva que constava de um roteiro com questões norteadoras para a elaboração de um relatório.

Durante a realização dos procedimentos em laboratório, todos os presentes utilizavam equipamentos de proteção individual. Os monitores podiam contar com a constante supervisão e orientação da professora e com o apoio de alguns materiais didáticos, como: o livro "Invertebrados" de Brusca et al. (2018), "Zoologia geral" de Storer et al. (1979) e "Invertebrados. Manual de aulas práticas" de Ribeiro-Costa et al. (2002).

A primeira atividade em laboratório, seguindo o cronograma da disciplina, teve como temática o Reino Protista, e consistiu na visualização de protozoários de vida livre através do microscópio óptico. A priori, explicou-se a função de cada estrutura do microscópio, sendo também disponibilizado um manual impresso para cada aluno. Para os experimentos em laboratório, os monitores coletaram em garrafas PET amostras de água de rio e lago, das quais os alunos colheram alguns mililitros com auxílio de uma pipeta e prepararam uma lâmina para ser visualizada no microscópio.

A aula prática posterior tratou do Reino Animalia e reforçou os conhecimentos sobre poríferos a partir de uma breve revisão dos tópicos mais importantes desse filo. Além disso, foi 
aprofundada a parte de sua anatomia, mais especificamente das espículas presentes no corpo da esponja. Para a visualização deste componente anatômico os alunos efetuaram o seguinte procedimento: pegar um pequeno fragmento do corpo da esponja, colocar em placa de petri e adicionar hipoclorito de sódio ou água sanitária; desse modo, quando a parte orgânica estivesse dissolvida, as espículas seriam visualizadas através do microscópio.

Assim como a práxis é importante para o aprofundamento do conteúdo de zoologia, a aula de revisão torna-se também uma grande aliada para fixação dos assuntos em momentos avaliativos. Com relação ao conteúdo sobre moluscos, foram realizadas as duas modalidades: a práxis, em laboratório, com a dissecação de um caracol (Achatina fulica), e uma aula de revisão anterior à avaliação escrita dos discentes.

A prática de dissecação também ocorreu ao fim do conteúdo sobre os anelídeos, e os representantes desse filo foram coletados pelos monitores e, no momento da aula, distribuídos para os discentes. Durante o procedimento, foram necessários alguns instrumentos, como: bisturis, pinças, béquer e um manual impresso sobre dissecação da minhoca, representante da Classe Oligochaeta. Antes de iniciar a dissecação, houve um momento para observação do comportamento locomotor e visualização de estruturas externas do animal, para que em seguida ele fosse anestesiado e seccionado, possibilitando a visualização de sua morfologia interna.

Após a aula teórica do Filo Arthropoda, foi ofertado um minicurso sobre montagem de caixas entomológicas. Para englobar a diversidade encontrada neste filo, essa atividade foi adaptada para a montagem de caixas, não apenas de insetos, mas também de aracnídeos, diplópodes e quilópodes. Além da revisão do conteúdo abordado, foi orientado durante o processo de confecção dessas caixas o que deveria estar presentes nelas, como também técnicas de alfinetagem para a fixação dos diferentes animais coletados.

\section{ReSUltados E DiscuSSÃo}

Para expor os benefícios decorrentes da monitoria acadêmica é necessário considerar todas as perspectivas e relações inseridas nesse contexto formativo no qual os monitores desfrutaram da oportunidade do contato com o meio docente, do aprimoramento de seu currículo e aprofundamento intelectual, colaborando com a dinâmica da disciplina e estabelecendo relação de confiança com a docente orientadora.

A interação entre monitores e discentes possibilitou significativa troca de saberes e experiências, já que os mesmos estiveram em uma posição semelhante e depois puderam assessorar o momento. Apesar de cada aula prática conter suas particularidades, observou-se 
que os alunos, em sua maioria, participaram ativamente das atividades propostas, demonstrando uma melhor assimilação de cada grupo de animais abordado, e também costumavam comentar que durante as aulas teóricas tinham dificuldades de entendimento do conteúdo em decorrência de sua extensão e detalhes.

Considerando as características mencionadas sobre os assuntos de zoologia, as aulas em laboratórios se tornam importantes, uma vez que foi perceptível, durante a avaliação descritiva, a facilidade dos alunos em fazerem o relatório a partir do que eles tinham realizado em cada atividade prática. Dessa maneira, Azevedo et al. (2012) considera que as referidas aulas são relevantes não apenas para complemento da teoria, mas por fornecerem um caráter mais lúdico que pode ser favorável para a participação ativa e interesse do discente.

Além de seus aspectos conteudísticos, a disciplina é composta por assuntos que podem surgir constantemente no dia a dia do estudante, mas que não são tangíveis ou mesmo passíveis de visualização, como é o caso dos protozoários. Nesse sentido, é evidente a importância do microscópio para que o discente consiga constatar uma configuração ao seu objeto de estudo.

A primeira prática laboratorial, que teve como assunto a observação dos protozoários, foi o momento em que os alunos monitorados tiveram a oportunidade de conhecer o espaço, seus principais equipamentos, e foram guiados na aquisição de conhecimento sobre o microscópio. Para muitos, foi a primeira visita àquele local, e era perceptível a atenção e curiosidade pelas informações passadas pela professora e pelos monitores, algo evidente principalmente no preparo das lâminas e manuseio do aparelho de microscopia.

Ao longo do procedimento, os discentes prepararam suas lâminas e levaram-nas para o microscópio, com o auxílio da professora e dos monitores, podendo então constatar a visualização de um dos representantes do filo Ciliophora como o de maior prevalência nas lâminas. Assim como ocorreu na pesquisa de Medeiros (2012), onde foram encontrados e caracterizados 65 táxons de protozoários durante a visualização em microscópio, sendo os pertencentes do filo Ciliophora o de maior ocorrência.

Assim como foi possível observar diferentes tipos de protozoários, os alunos também tiveram participação ativa na práxis para visualização de um constituinte corporal dos poríferos (esponjas). Como afirma Almeida et al. (2009), as esponjas possuem um esqueleto de sustentação, denominado de espículas. Estas são componentes anatômicos primordiais no estudo deste filo e são melhores visualizadas através do microscópio. 
Neste procedimento foi aprendido, primeiramente, como dissolver a parte orgânica do animal para que fosse possível a dispersão das espículas nas lâminas. Este método demostrou ser de fácil compreensão para os que estavam presentes e para os que prepararam o material, logo, esta aula obteve resultados satisfatórios, já que todos os presentes conseguiram cumprir um dos objetivos da aula: observar uma espícula (Figura 1). A relevância desta metodologia é verificada no estudo de Alves et al. (2016), que relata a aplicação desse procedimento em espécies de esponjas coletadas na Bacia de Potiguar. Assim, a identificação taxonômica desses animais ocorreu através da análise de lâminas de espículas e, deste modo, foi possível reconhecer uma nova espécie do gênero Erylus na costa brasileira.

Figura 1 - Fotografia da lente do microscópio de uma lâmina preparada e observada por um discente, possibilitando a visualização de espículas

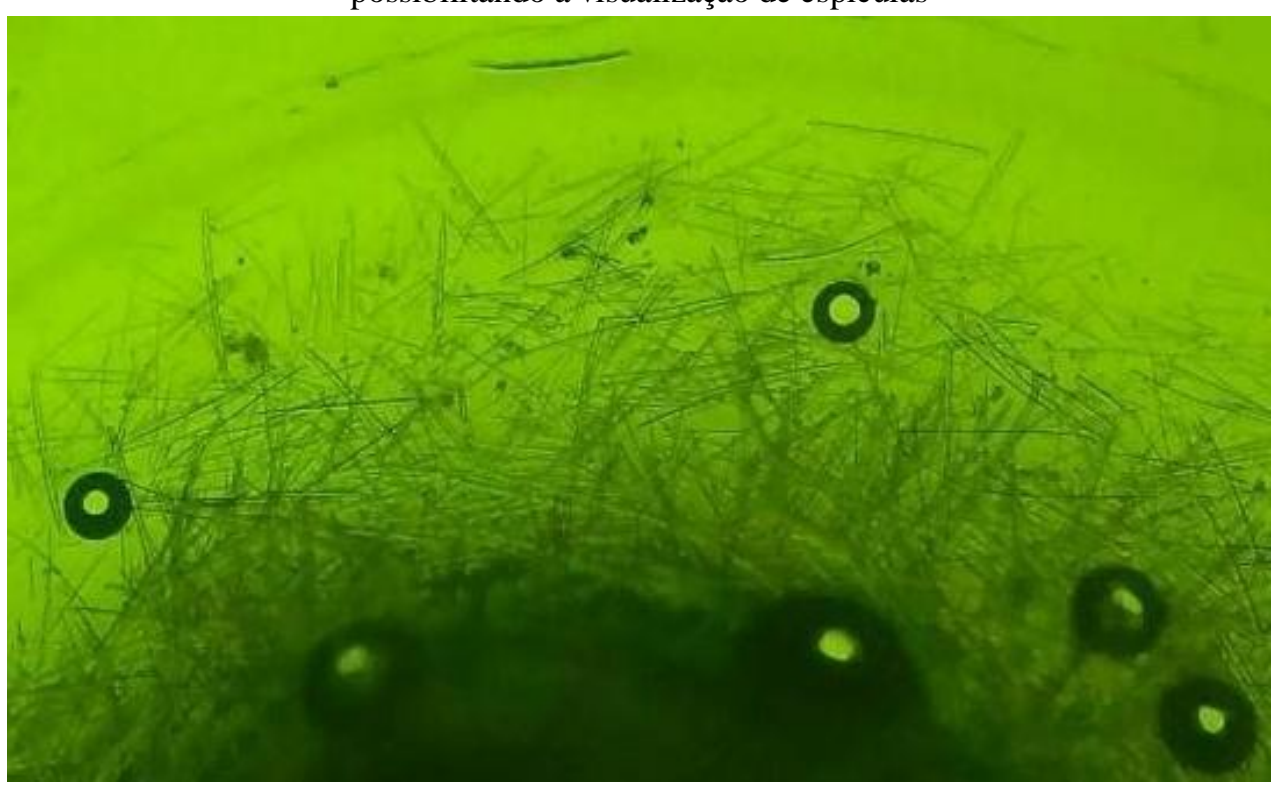

Fonte: Aula prática do Filo Porifera (2019).

Em um trabalho desenvolvido por Frison (2016), oito dos nove monitores que entrevistou declararam que as atividades de monitoria utilizam diversas estratégias para despertar o interesse do discente no aprofundamento dos assuntos dispostos nas disciplinas. Entre essas estratégias estão as revisões de conteúdo, que podem acontecer no desenrolar das práticas e também como aula expositiva, que foi o caso de algumas atividades desenvolvidas pelos autores deste artigo.

Neste seguimento, foi disponibilizado esta modalidade de aula para que os discentes tivessem um momento para sanar dúvidas, fixar e aprimorar uma parcela significativa dos assuntos. O estudo de Matias et al. (2018) considerou que o uso de tecnologias em sala de aula é mais atrativo e motivacional para os discentes, porém, devido à limitação de recursos na 
universidade, não foi sempre que os monitores conseguiram utilizar materiais modernos, como projetor multimídia, tendo que fazer uso de objetos mais tradicionais, mas tentando tornar a explicação a mais didática e descomplicada possível, com representações em desenho, tópicos e questionamentos direcionados.

Atribui-se também ao ensino prático de zoologia dos invertebrados atividades de dissecação, que, neste caso, foram desenvolvidas em laboratório e aplicadas aos animais representantes dos gastrópodes, do filo Mollusca e dos oligoquetos, do filo Annelida (Figura 2). No momento de apresentação desta aula, foi possível identificar a curiosidade quanto aos materiais e concentração nas explicações de preparo. Como aponta Greif (2003), esta prática promove aprendizado técnico sobre a anatomofisiologia do animal dissecado e chama a atenção do aluno, que, além de todo o conhecimento específico adquirido, passa a ser cativado pela ciência e se interessar por esses assuntos.

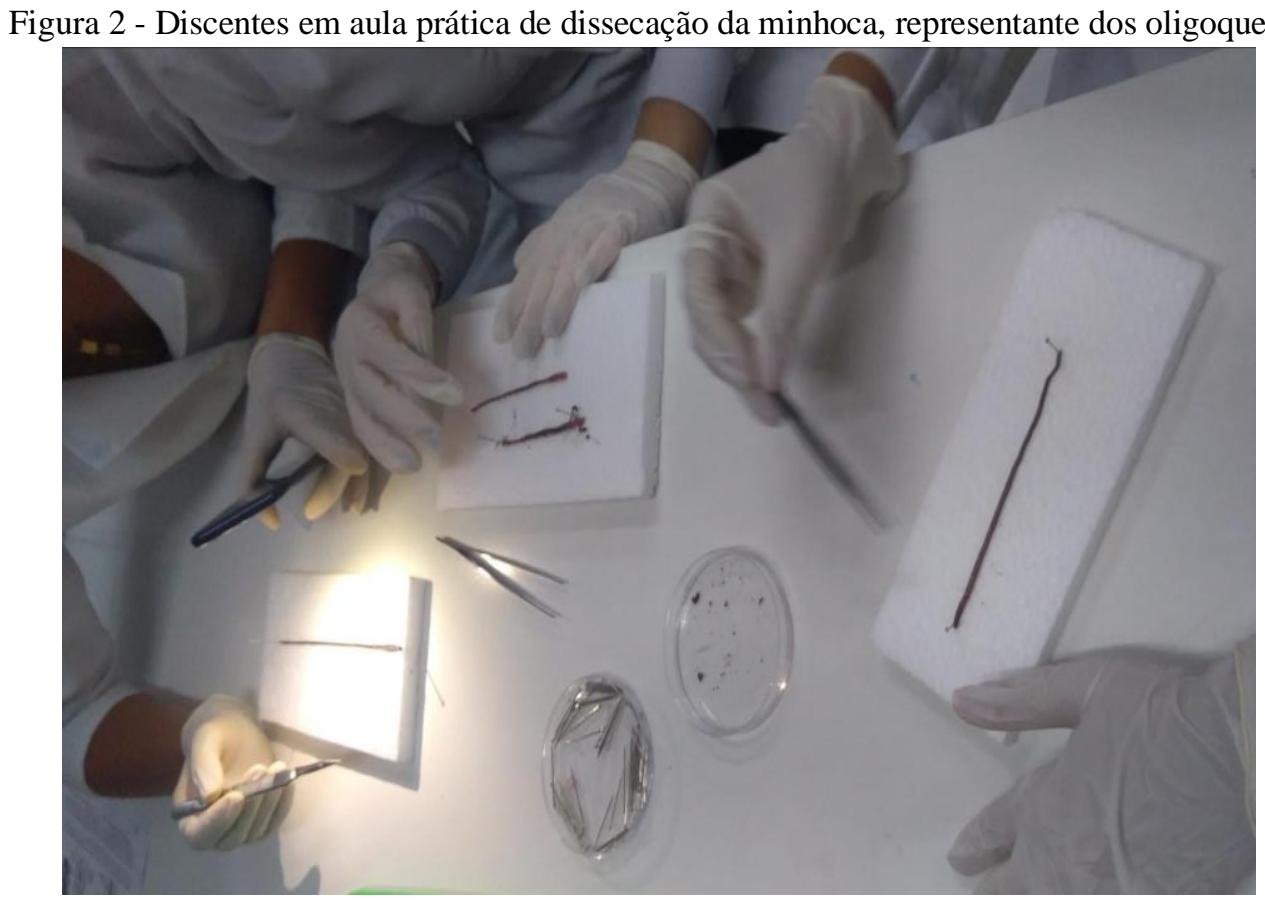

Fonte: Aula prática do Filo Annelida (2019)

No decorrer das etapas, muitos estudantes não conseguiram obter sucesso na secção do corpo do animal, mesmo com manual e aparelhagem adequada, pois a dimensão e sensibilidade das estruturas corporais desta espécie dificultaram, para alguns, o êxito nesta prática. Para outros, as etapas para a dissecação foram concluídas e possibilitaram a visualização de algumas estruturas internas, resultado observado no trabalho de Ritchter e colaboradores (2014), em que a aula prática desenvolvida propiciou aos alunos a identificação de órgãos e suas respectivas funções, bem como a articulação de discussões sobre a teoria e prática. 
Alguns autores consideram a substituição de material biológico para o ensino de animais e propõem algumas alternativas para o uso dos mesmos. Furlan e Fischer (2020) destacam alguns recursos didáticos, como: o uso de modelos, softwares e materiais audiovisuais. Nesse mesmo viés, Arouca (2007) apresenta uma possibilidade de dissecação sem utilizar o animal vivo, mas usando-o de forma virtual, através do programa World Wide Web, essa demonstração de dissecação é vantajosa por permitir repetições, não possuir muitos custos materiais, possibilitar a efetivação desta prática por todos os alunos e não apresentar o problema de danificar a espécie.

O estudo de Arouca (2007) ainda informa a necessidade de computadores para todos os alunos na realização da dissecação virtual, e é neste ponto que a utilização desse e outros meios tecnológicos tornam-se inviáveis, pois, na experiência de ensino que resultou na escrita do presente trabalho, um planejamento com essas técnicas inovadoras representaria o desenvolvimento de uma aula sem garantia de realização, já que é comum a limitação desses recursos. Esta autora também expõe que alguns alunos veem a dissecação real como mais motivadora, visto que nela pode-se ter um contato legítimo com a espécie e com os instrumentos necessários.

Nessa perspectiva, o contato com as espécies também se torna viável em práticas que envolvem o filo Arthropoda, e tal conduta foi proporcionada com um minicurso que objetivou aprimorar o conhecimento e habilidades dos discentes para a consumação da atividade prática. Segundo Farias et al. (2020) o minicurso é um instrumento importante na propagação de conhecimento, uma vez que tem a possibilidade de utilizar diferentes recursos metodológicos para explorar o conteúdo a ser abordado.

Desse modo, esta atividade possibilitou que a diversidade do filo Arthropoda fosse conhecida, coletada, conservada, identificada e exposta em caixas, que seriam grandes contribuintes no estudo deste filo. Foram confeccionadas cinco caixas de artrópodes por cinco grupos de alunos e apesar da docente deixar à critério da disponibilidade e criatividade dos discentes a escolha dos animais, a maioria das caixas apresentou uniformidade, sendo os insetos os artrópodes mais comumente selecionados (Figura 3). 
Figura 3 - Caixas de artrópodes confeccionadas pelos discentes da disciplina de Zoologia dos Invertebrados II

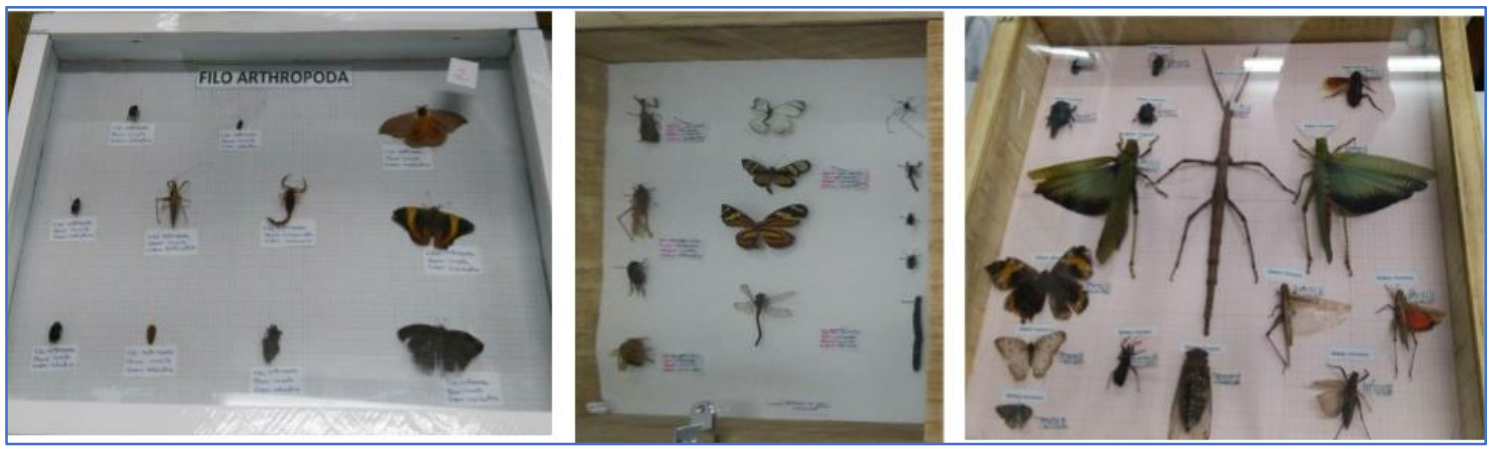

Fonte: Aula prática do Filo Arthropoda (2019).

Fornecer esse método prático aos licenciandos pode influenciá-los e capacitá-los a reproduzir essa base metodológica, se for o caso, quando assumirem o lugar de professores na educação básica. Nessa perspectiva, Glória et al. (2019) descreve que as etapas desenvolvidas na construção da caixa entomológica contribuem para a visualização da morfologia externa, para o estabelecimento da relação entre o nome científico e popular, conhecimento sobre as espécies existentes no local e qual sua relação com este meio. Em seu trabalho, a autora afirma que a experiência da captura de insetos, a aula de campo e todo o processo de confecção da caixa entomológica tornaram a aprendizagem mais significativa.

\section{CONSIDERAÇÕES FINAIS}

A experiência de atuação na monitoria relatada neste trabalho tornou possível constatar que o contato do acadêmico monitor com diferentes aspectos da disciplina, em suas facetas: científica, teórica, prática e social, contribuiu tanto para sua própria formação como para um melhor andamento da disciplina, favorecendo o desenvolvimento das metodologias aplicadas.

Pode-se destacar nesse processo experiências formativas como o planejamento, a conduta, a participação e a mediação nas aulas práticas, aspectos relevantes na aquisição de conhecimentos específicos e habilidades metodológicas para a formação e exercício da docência. Além disso, a monitoria foi uma experiência enriquecedora, pois foi possível observar de uma forma concreta, as adversidades e facilidades enfrentadas na experiência da docência e a interação entre os acadêmicos como fator necessário e decisivo para que ocorra uma melhor interação na disciplina.

Por fim, constatou-se que os monitores, ao auxiliarem o professor nas aulas de forma consciente e participativa, facilitam o acesso dos alunos aos conteúdos e métodos da disciplina, tornando as experiências de ensino mais dinâmicas e participativas, fatores estes primordiais para o sucesso da aprendizagem. 


\section{REFERÊNCIAS}

ALMEIDA, Ariana Cristina Santos; VOLKMER-RIBEIRO, Cecília; VARAJÃO, Angelica Fortes Drummond Chicarino; GOMES, Newton Souza; VARAJÃO, César Augusto Chicarino. Espículas de esponjas continentais nos sedimentos cenozóicos do noroeste de Minas Gerais, como indicadores paleoambientais. Revista Brasileira de Paleontologia, v. 12, n. 2, p. 123-138, 2009. DOI:10.4072/rbp.2009.2.03

ALVES, Rodrigo Vinícius de Almeida.; SANTOS, George Garcia; PINHEIRO, Ulisses. Uma nova espécie de Erylus Gray, 1867 para o Brasil. In: ALMEIDA, Alexandre Oliveira; SILVA, Catarina de Lourdes Araújo; LUCATELLI, Débora; ALVES JÚNIOR, Flavio Almeida; ARAÚJO, Marina de Sá Leitão Câmara de. Livro de Resumos do XIX Encontro Nordestino de Zoologia - EZN. Garanhuns, 2016.

ARAÚJO-DE-ALMEIDA, Elineí; SANTOS, Roberto Lima; SILVA, Clécio Danilo Dias da; MELO, Gisele Silva Marques de; D'OLIVEIRA, Rosângela Gondim. Inovações didáticas no ensino de zoologia: enfoques sobre a elaboração e comunicação de relatos de experiências como atividades de aprendizagem. Brazilian Journal of Development, v. 5, n. 6, p. 66996718, 2019. https://doi.org/10.34117/bjdv5n6-164

ARAÚJO-DE-ALMEIDA, Elineí; D’OLIVEIRA, Rosângela Gondim; MENDES, Liana de Figueiredo; FREIRE, Eliza Maria Xavier. Interações pedagógicas em Zoologia e o enfoque metadisciplinar. In: ARAÚJO-DE-ALMEIDA, E. (Org.). Ensino de zoologia: ensaios metadisciplinares. João Pessoa: EdUFPb, 2011. p.63-78.

ARAÚJO-DE-ALMEIDA, Elineí. Registros e divulgação de experiências efetivadas no ensino: práticas motivadoras na trajetória do professor e dos estudantes. Revista Barbante, v. 1, n.3, p. 1-10, 2012.

AROUCA, Susana Patrícia de Sousa. Dissecação virtual on-line vs. Dissecação Real: "Um estudo comparativo no Ensino Básico". 2007. Porto: Dissertação (Mestrado em Educação Multimédia) - Faculdade de Ciências da Universidade do Porto, Departamento de Química. Porto, 2007. Disponível em: https://repositorio-aberto.up.pt/handle/10216/64119. Acesso em: 23 mar. 2021.

ASSIS, Fernanda de; BORSATTO, Alessandra Zanei; SILVA, Pâmela Duarte Dias da; PERES, Patrícia de Lima; ROCHA, Patrícia Rodrigues; LOPES, Gertrudes Teixeira. Programa de monitoria acadêmica: percepções de monitores e orientadores. Rev. Enferm. Uerj, v. 14, n.3, P. 391-397, 2006.

AZEVEDO, Hugo José C. C.; FIGUEIRÓ, Ronaldo; ALVES, Dimitri Ramos; VIEIRA, Valéria; SENNA, André R. O uso de coleções zoológicas como ferramenta didática no ensino superior: um relato de caso. Revista Práxis, v. 4, n. 7, p. 43-48, 2012.

https://doi.org/10.25119/praxis-4-7-548

BRUSCA, Richard C.; MOORE, Wendy; SHUSTER, Stephen M. Invertebrados. Rio de Janeiro: Guanabara Koogan, 2018.

CONGRESSO NACIONAL (BR). Lei $\mathrm{n}^{\circ}$ 5540, de 28 de novembro de 1968. Boletim da Universidade do Estado da Guanabara de 31 de novembro de 1968. Rio de Janeiro (RJ): 
Universidade do Estado da Guanabara, 1968. Disponível em:

https://www2.camara.leg.br/legin/fed/lei/1960-1969/lei-5540-28-novembro-1968-359201publicacaooriginal-1-pl.html. Acesso em: 23 mar. 2021.

CONGRESSO NACIONAL (BR). Lei nº 9394, de 20 de dezembro de 1996. Boletim da Universidade do Estado da Guanabara de 31 de novembro de 1968. Rio de Janeiro (RJ): Universidade do Estado da Guanabara, 1996. Disponível em: https://www2.camara.leg.br/legin/fed/lei/1996/lei-9394-20-dezembro-1996-362578publicacaooriginal-1-pl.html. Acesso em: 23 mar. 2021.

DIAS-DA-SILVA, Clécio Danilo. Potencialidades dos mapas conceituais no processo de ensino-aprendizagem de zoologia. 2018. Natal: Dissertação (Pós-graduação em Ensino de Ciências Naturais e Matemática)- Universidade Federal do Rio Grande do Norte, Natal, 2018. Disponível em: https://repositorio.ufrn.br/jspui/handle/123456789/26270. Acesso em: 23 mar. 2021.

FARIAS, Daniella Carvalho ; NEVES, Maria Aparecida; KOWALCZUK, Vânia Graciele Lezan. As atividades práticas para o ensino aprendizagem de artrópodes no ensino médio. Brazilian Journal of Development, v. 6, n. 11, 2020. https://doi.org/10.34117/bjdv6n11-502

FERNANDES, Juliana; ABREU, Thaynara Alves; DANTAS, Anne Joyce Lima; SILVA, Angélica Maria de Sousa. Influência da Monitoria Acadêmica no Processo de Ensino e Aprendizagem da Psicologia. Clínica \& Cultura, v.2, n.1, p. 36-43, 2016.

FURLAN, Ana Laura Diniz; FISCHER, Marta Luciane. Métodos alternativos ao uso de animais como recurso didático: um novo paradigma bioético para o ensino da zoologia. Educação em Revista, v. 36, 2020. https://doi.org/10.1590/0102-4698230590

FRISON, Lourdes Maria Bragagnolo. Monitoria: uma modalidade de ensino que potencializa a aprendizagem colaborativa e autorregulada. Revista Pro-posições, v. 27, p. 133-153, 2016. https://doi.org/10.1590/0103-7307201607908

GLÓRIA, Isabela Acássia de Souza. Aula prática como ferramenta pedagógica para aprendizagem significativa no ensino de zoologia.2019. Paritins: Monografia ( licenciatura em ciências biológicas)- Universidade do Estado do Amazonas, Paritins, 2019. Disponível em:http://repositorioinstitucional.uea.edu.br/bitstream/riuea/1729/1/Aula\%20pr\%c3\%a1tica\% 20como\%20ferramenta\%20pedag\%c3\%b3gica\%20para\%20aprendizagem $\% 20$ significativa $\%$ 20no\%20ensino\%20de\%20zoologia..pdf. Acesso em: 23 mar. 2021.

GREIF, Sérgio. Alternativas ao uso de animais vivos na educação pela ciência responsável. São Paulo: Instituto Nina Rosa, 2003.

LIRA, Morgana Oliveira; NASCIMENTO, Denise de Queiroga; SILVA, Geilza Carla de Lima; MAMAN, Aline dos Santos de. Contribuições da monitoria acadêmica para o processo de formação inicial docente de Licenciandos em Ciências Biológicas da UEPB. In: II Congresso Nacional (ISSN 2358-882), Anais...Campina Grande, 2015. Disponível em: https://editorarealize.com.br/artigo/visualizar/15677. Acesso em: 23 mar. 2021. 
MATIAS, Ana Luíza Machado; FARIA, Ana Vitória Guimarães.; MARTINS, Angélica Pereira. Tecnologia em sala de aula: uma realidade urgente aos olhos dos alunos do século XXI. Revista Crátilo, v.11, n.2, p. 43-55, 2018.

MINISTÉRIO DA EDUCAÇÃO. Diretrizes Curriculares Nacionais dos cursos de Filosofia, História, Geografia, Serviço Social, Comunicação Social, Ciências Sociais, Letras, Biblioteconomia, Arquivologia e Museologia. Distrito federal, 2001. Disponível em: http://portal.mec.gov.br/cne/arquivos/pdf/CES0492.pdf. Acesso em: 23 mar. 2021.

MEDEIROS, Maria Luisa Quinino de. Protozoários de Vida Livre em Ambientes Aquáticos do RN: ocorrência, caracterização e importância para a educação básica. Dissertação (Mestrado em Desenvolvimento e Meio Ambiente) - Faculdade de Ciências Biológicas, Universidade Federal do Rio Grande do Norte, Natal, 2012. Disponível em: https://repositorio.ufrn.br/handle/123456789/18229. Acesso em: 23 mar. 2021.

NUNES, João Batista Carvalho. Monitoria acadêmica: espaço de formação. In: SANTOS, Mirza Medeiros dos; LINS, Nostradamus de Medeiros. A monitoria como espaço de iniciação à docência: possibilidades e trajetórias. Natal: EDUFRN, 2007. p. 45-58.

PASSEGGI, Maria da Conceição. Narrativas da experiência na pesquisa-formação: do sujeito epistêmico ao sujeito biográfico. Roteiro, v. 41, n. 1, p. 67-86, 2016.

https://doi.org/10.18593/r.v41i1.9267.

RAMALHO, Betânia Leite. Reflexões sobre o ensino e o exercício da docência no ensino superior. ForGRAD em revista, n. 1, p.26-32, 2006.

RIBEIRO-COSTA, Cibele Stramare; ROCHA, Rosana Moreira da. Invertebrados: manual de aulas práticas. Ribeirão Preto: Holos, 2002.

RICHTER, Elivelto; GÜLLICH, Roque Ismael da Costa; FRÖHLICH, Tatiana Roberta Venzke. Trabalhando durante a iniciação à docência em Ciências com variadas modalidades didáticas no estudo dos Invertebrados. Revista da SBEnBio, v. 7, 2014.

SILVA, Meris Oliveira; SILVA, Cícera Firmina; SANTOS, Ednalva Alves Vital. As possibilidades da monitoria para a formação docente: um relato de experiência no curso de ciências biológicas. Educação, Ciência e Saúde, v. 5, n. 2, 2018.

http://dx.doi.org/10.20438/ecs.v5i2.147

SILVEIRA, Eduardo; SALES, Fernanda de. A importância do Programa de Monitoria no ensino de Biblioteconomia da Universidade do Estado de Santa Catarina (UDESC). Rev. Ci. Inf. e Doc., v. 7, n. 1, p. 131-149, 2016. https://doi.org/10.11606/issn.2178-2075.v7i1p131$\underline{149}$

STORER, Tracy Irwin; USINGER, Robert Leslie. Zoologia Geral. São Paulo: Companhia Editora Nacional, 1979.

SUÁREZ, Daniel Hugo; FLORES, Ignácio Rivas. La investigación narrativa, la formación y la práctica docente. Revista del IICE, n. 41, p. 5-14, 2017. 
ZEN, Eduardo Pedro; LINZMEIER, Adelita Maria. A EXTENSÃO A PARTIR DA MONITORIA. Seminário Integrador de Extensão, v. 1, n. 1, 2018.

https://doi.org/10.18593/r.v41i1.9267 